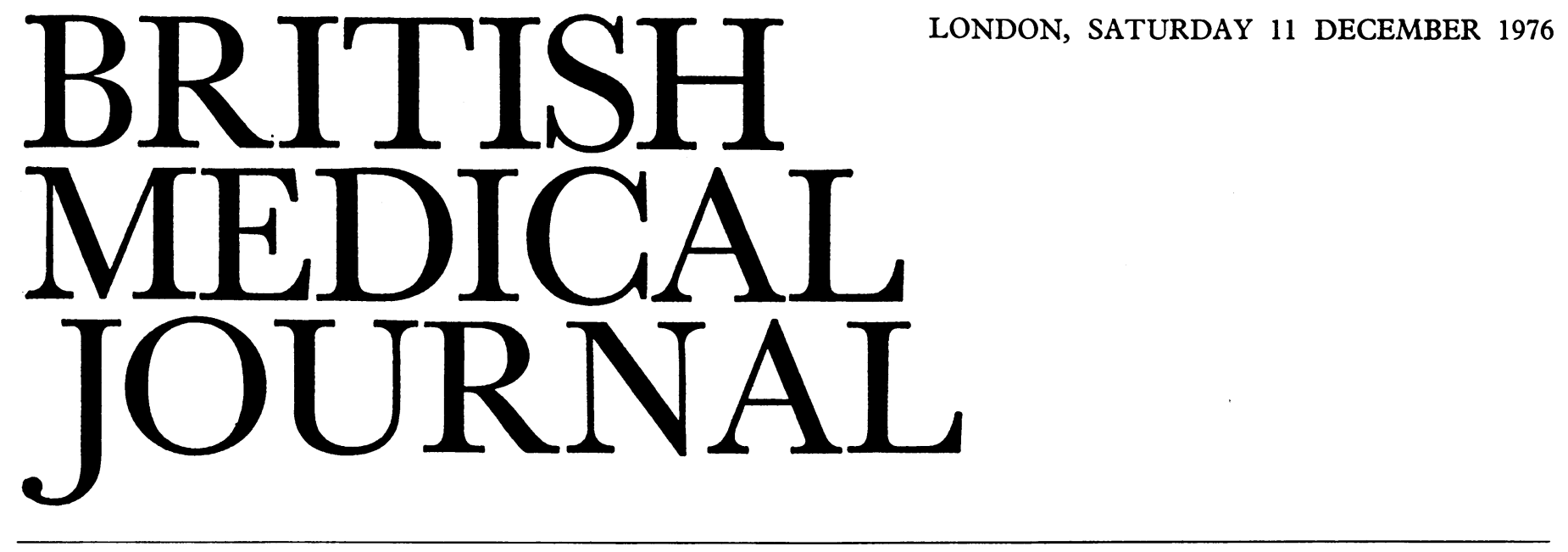

\title{
Born before their time into this breathing world
}

The perinatal period is a testing time for the young of all species, including our own. Mortality in human newborn infants is mainly the result of hypoxia, and after birth a major cause is pulmonary immaturity, which presents the clinical picture of the so-called Idiopathic Respiratory Distress Syndrome of the premature infant (RDS). Despite improvements in management stemming from better understanding of its physiopathology, ${ }^{12}$ this condition probably remains the single largest cause of death in babies born alive without important congenital defects, ${ }^{3}$ and there is also a considerable morbidity in survivors. Fortunately the prognosis as regards brain function is good, ${ }^{4}$ but semipermanent lung changes have been described in babies requiring artificial ventilation at high pressures in high oxygen concentrations, ${ }^{5}$ and battering is known to occur with undue frequency as a consequence of separation of babies from their mothers during treatment. ${ }^{6}$ Furthermore, the intensive care units in which these babies are nursed are expensive in terms of the staff and equipment required.

Clearly prevention would be better than intensive care, but the prematurity rate has not fallen with the birth rate $^{7}$ and may even rise with the present fashion for induction of labour, ${ }^{8}$ while in many cases premature delivery is necessary for the well-being of mother or child. In these circumstances a more promising approach is the search for ways of speeding up pulmonary maturity, which it is now known is mainly a matter of the adequacy of surfactant secretion into the alveoli by type II pneumocytes. In the absence of surfactant the alveoli are unstable, tending to collapse during expiration, and it is this effect, which greatly increases the work of breathing, that leads either to death from exhaustion in the more feeble or severely affected patients or at very least a debilitating illness at a critical time in survivors.

The possibility of inducing premature surfactant secretion arose from the work of Liggins, who observed that when labour was prematurely induced by the use of glucocorticoids in sheep the lambs so born did not develop the respiratory distress that would have been predicted from laboratory experience at their stage of gestation. ${ }^{9}$ There are important differences in the pattern of maturation in the human fetus: surfactant secretion seems to begin quite early in gestation, almost before the baby is viable in other respects ${ }^{10}$; but, nevertheless, there is a surge in production at about the 34 th week $^{11}$ coincident with a rise in fetal cortisol levels. This rise is reflected in the amount of surfactant carried by lung liquid flowing into the amniotic fluid ${ }^{12}$; and subsequently respiratory distress does not occur or is mild. The length of time from conception is not the only factor, however: there are differences in incidence between first and second twins ${ }^{13}$ - the latter being notoriously more susceptible, between the two sexes, ${ }^{14}$ and according to a baby's state at birth, ${ }^{1516}$ while respiratory distress may also occur in apparently term babies and is not invariable even in the extremely immature. It seems that some conditions (including exposure to certain drugs in utero, ${ }^{17}$ maternal toxaemia, intrauterine infection, premature rupture of the membranes, and even normal labour) advance pulmonary maturation, while others (particularly uncontrolled maternal diabetes) retard it. ${ }^{18}$ Thus it is of interest that in tissue culture insulin and cortisol appear to have opposite effects on surfactant secretion ${ }^{19}$ as they do on the induction of the urea cycle enzymes $^{20}$ and of glycogen storage in the fetal liver ${ }^{21}$; and this may reflect a fundamental conflict between growth and maturation including that of the brain. That the effect of diabetes is not straightforward is shown by the conflict of opinion on its effect on the incidence of RDS and in anomalies of lung histology in which there is evidence of both advanced maturation and delayed surfactant secretion.

Against this background knowledge must be viewed the use of steroids in promoting pulmonary maturation in the infant before premature delivery. Liggins ${ }^{22}$ went on from his work in animals to organise a carefully monitored clinical trial in Auckland and has published preliminary results which suggest that in babies born before the 32nd week of gestation there is a beneficial effect from the use of betamethasone (a synthetic steroid not all of whose actions are similar to those of equivalent doses of cortisol). Further experience in Auckland has apparently confirmed these preliminary observations, but the incidence of RDS there is low, and few deaths in the control series appear to have been due to hyaline membrane disease. A worrying feature is a possible increase in deaths in utero of the babies of toxaemic mothers treated with betamethasone, reminiscent of earlier observations on the effects of therapeutic steroids given in pharmacological doses for long periods during pregnancy. ${ }^{23}$

Liggins's results have now been confirmed by further studies undertaken in France ${ }^{24}$ and Israel, ${ }^{25}$ and the Israeli workers in particular have reported a striking diminution in mortality in the babies of treated women in a unit where the incidence and death rate of RDS seemed to be particularly high. No important side effects were observed from either the betamethasone used to promote pulmonary maturation or the isoxopine used to suppress labour during treatment, the best results being obtained when fetal exposure lasted at least three days. 
Clearly in certain circumstances treatment with betamethasone may be very beneficial and the benefits may outweigh the short-term risks. Of long-term risks we know nothing, but the record of perinatal medicine in this respect is not reassuring -with deafness, blindness, and cancer among the side effects of treatment used in good faith and for good reasons in various conditions from threatened abortion to early infection. Certainly in the fetus steroids play a major part in ordering normal development, and there is not only the problem of their action before birth but their suppression afterwards to consider. ${ }^{26}$ Meanwhile, a high standard of care in the antenatal clinic and at birth is the best way of ensuring a low mortality from respiratory distress rather than the general introduction of either betamethasone prophylaxis or of intensive care of affected infants, which is most economic when centralised in referral units.

1 Roberton, N C, and Tizard, J P M, British Medical fournal, 1975, 3, 271.

2 Prod'hom, L S, et al, Pediatrics, 1974, 53, 170.

${ }^{3}$ Chamberlain, R, British Births, 1970, vol 1, p 238. London, Heinemann, 1975.

${ }^{4}$ Dinwiddie, R, et al, Archives of Disease in Childhood, 1974, 49, 703.

5 Stocks, J, and Godfrey, S, Pediatrics, 1976, 57, 352

${ }^{6}$ Lynch, M, Lancet, 1975, 2, 317.

7 DHSS, Health and Personal Social Service Statistics for England, 1975, p 131. London, HMSO, 1976.

${ }^{8}$ Fanaroff, A, et al, Year Book of Pediatrics 1976, ed S Gellis, p 7. Chicago, Year Book Medical Publishers, 1976.

${ }^{9}$ Liggins, C G, in Foetal Autonomy, (CIBA Foundation Symposium) ed G E W Wolstenholme and M O'Connor, p 218. London, Churchill, 1969.

10 Gluck, L, et al, Pecïatric Research, 1972, 6, 81.

${ }_{11}$ Schirar, A, et al, American fournal of Obstetrics and Gynecology, 1975, 121, 653.

12 Sproule, W B, Greene, M E, and Whitfield, C R, American fournal of Obstetrics and Gynecology, 1974, 119, 653.

13 Rokos, J, et al, Pediatrics, 1968, 42, 204.

14 Pearson, R, Lancet, 1976, 1, 60.

15 Omer, M A, Robson, E, and Neligan, G A, Archives of Diseases in Childhood, 1974, 49, 219.

${ }^{16}$ James, L S, New England fournal of Medicine, 1975, 292, 1291.

17 Chiswick, M, Archives of Disease in Childhood, 1976, in press.

18 Boughton, K, Gandy, G, and Gairdner, D, Archives of Disease in Childhood, 1970, 45, 311 .

19 Smith, B T, et al, fournal of Pediatrics, 1975, 87, 953

${ }^{20}$ Raiha, N C P, and Edkinse, E, Communication to E S P R, Rotterdam, 1976.

${ }^{21}$ Sparks, J W, Lynch, A, and Glinsmann, W, Pediatric Research, 1976, 10, 415.

${ }^{22}$ Liggins, G C, and Howie, R N, Pediatrics, 1972, 50, 515.

23 Warrell, D W, and Taylor, R E, Lancet, 1968, 1, 117

24 Fargier, P, et al, Novvelle Presse Médicale, 1974, 3, 1595.

${ }_{25}$ Nathan, D M, Mount Sinai fournal of Medicine, New York, 1975, 42, 150.

26 Osathanondh, R, et al, Pediatric Research, 1976, 10, 342.

\section{The fetal alcohol syndrome}

Alcohol drunk in excess by expectant mothers is a powerful cause of growth retardation and congenital malformations. The evidence for this statement comes from anecdotal clinical reports ${ }^{1-6}$ and from animal experiments. ${ }^{78}$ So far, though, we have no evidence that social drinking constitutes any risk to the fetus: all the women concerned have been heavy drinkers before and during their pregnancies. In some cases they had complications of alcoholism such as cirrhosis, anaemia, chronic undernutrition, and delirium tremens, ${ }^{2356}$ and some were in an alcoholic stupor at the time of delivery. ${ }^{26}$ Generally they came from the lower socioeconomic groups, were multiparous, and in their late 20 s or older.

Maternal alcoholism seems to produce a definite fetal syndrome with features which, though not unique, should arouse suspicion. In most accounts 256 the affected children have had maxillary hypoplasia, with prominence of the forehead and lower jaw, short palpebral fissures, small eyes and epicanthic folds, and in some cases a squint or unilateral ptosis. There is severe intrauterine growth retardation. The infants are both short and light for dates, and the growth potential in childhood is poor. Almost all children have had microcephaly and mental retardation and some infants have had obvious tremulousness, not responding to sedation, and persisting into childhood with incoordination and poor gross motor performance. ${ }^{2}$ Many children were investigated in hospital or placed with foster parents because of failure to thrive, but none of these showed any real improvement in growth or mental development. ${ }^{25}$

There is some variety in the other anomalies that occur. Congenital heart disease including ventricular septal defect is common, while skin capillary haemangiomata, deficient upper helices of the ears, low set ears, dislocation of the hips, restriction of movement of some joints, abnormal palmar creases, overlapping of the fingers, and (in two cases) hirsutism ${ }^{4}$ have all been reported. In the early descriptions the authors considered the possibility of other syndromes before they diagnosed the fetal alcohol syndrome. Thus one of the patients reported by Jones and $\mathrm{Smith}^{3}$ was originally thought to have the Cornelia de Lange and the other the trisomy-18 syndrome, and the patient reported by Hall and Orenstein ${ }^{9}$ was thought to have Noonan's syndrome. Possibly other patients may not yet have been correctly diagnosed.

Circumstantial evidence for the adverse effects of maternal alcoholism seems to have existed for some time, ${ }^{3}$ but confirmation has been slow. Perhaps this is because the incidence of maternal alcoholism is itself low: in the report of Jones et al ${ }^{4}$ only 23 women out of 55000 mothers were regarded as definitely alcoholic. Nevertheless, the incidence seems variable: out of 1594 pregnant women in a poor urban population reviewed by Ulleland, 12 were alcoholic. ${ }^{1}$ The risk of fetal death and malformation seems high. Of 23 babies, four died, and the 13 offspring were smaller than controls and six had malformations typical of the fetal alcohol syndrome. ${ }^{4}$ Ten of the 12 infants reported by Ulleland ${ }^{2}$ were undersized. This high incidence of damage has been further confirmed by Shruygin's study, ${ }^{10}$ in which over half the children born to alcoholic mothers were mentally retarded.

Of great practical clinical importance are those children who might be partially affected ${ }^{2}$ and who may not be recognised until a more severely affected sibling is born. Certainly more than one child in a family may be affected. One patient, whose mental retardation was attributed to asphyxia, ${ }^{6}$ was not recognised as suffering from maternal alcoholism until his younger brother was born. Re-examination showed a convergent squint, some limitation of joint mobility, and short palpebral fissures. In another instance a younger sibling from a different father was also found to be affected, ${ }^{3}$ and. Palmer et $a l^{5}$ reported a family of four children of whom three were affected. Clearly recognition of the syndrome may prevent recurrence, though, even when suspected, alcoholism may be difficult to confirm ${ }^{14}$ and to treat.

Evidence from animal studies of the teratogenic effects of alcohol is growing, though an early report by Papara-Nicholson and Telford ${ }^{7}$ of the production of low birthweight litters in guinea-pigs was not confirmed in the rabbit. ${ }^{11}$ Chernoff, ${ }^{8}$ however, has now reported embryo resorption and low birthweight fetuses with skeletal, eye, cardiovascular, and central nervous defects in pregnant mice fed high-alcohol diets.

Other factors are associated with this syndrome-in particular heavy smoking by the mothers, poor maternal nutrition, 